\title{
Numerical Comparison by Different Methods (Second Order Runge Kutta Methods, Heun Method, Fixed Point Method and Ralston Method) to Differential Equations with Initial Condition
}

\author{
Comparación numérica por diferentes métodos (métodos Runge Kutta de segundo \\ orden, método Heun, método de punto fijo y método Ralston) a ecuaciones \\ diferenciales con condición inicial
}

\author{
F. Mesa ; D. M. Devia- Narvaez iD ; G. Correa-Vélez iD
}

\begin{abstract}
This manuscript contains a detailed comparison between numerical solution methods of ordinary differential equations, which start from the Taylor series method of order 2, stating that this series hinders calculations for higher order derivatives of functions of several variables, so that the Runge Kutta methods of order 2 are implemented, which achieve the required purpose avoiding the cumbersome calculations of higher order derivatives. In this document, different variants of the Runge-Kutta methods of order 2 will be exposed from an introduction and demonstration of the connection of these with the Taylor series of order 2, these methods are: the method of Heun, the method of midpoint and the Ralston method. It will be observed from the solution of test differential equations its respective error with respect to the analytical solution, obtaining an error index dictated by the mean square error EMC. Through this document we will know the best numerical approximation to the analytical solution of the different PVI (initial value problems) raised, also fixing a solution pattern for certain problems, that is, the appropriate method for each type of problem will be stipulated. It was observed that the Ralston method presented greater accuracy followed by the midpoint method and the Heun method, in the other PVI it is observed that the midpoint method yields the best numerical solution since it has a very low EMC and difficult to reach by the other methods.
\end{abstract}

Index Terms - analytical solution, approximation, differential equations, Heun, initial value problems, midpoint, numerical solution, Ralston, series.

Resumen-Este documento contiene una comparación detallada entre los métodos de solución numérica de las ecuaciones diferenciales ordinarias, que comienzan con el método de la serie Taylor de orden 2, indicando que esta serie dificulta los cálculos para derivadas de orden superior de funciones de varias variables, de modo que los métodos de orden Runge Kutta 2 se implementan, lo que logra el propósito requerido evitando los difíciles cálculos de derivadas de orden superior. En este documento, se expondrán

This manuscript was sent on November 26, 2018 and accepted on March 24, 2020. F. Mesa; D. M. Devia-Narvaez; G. Correa- Velez work as professors of diferentes variantes de los métodos Runge-Kutta de orden 2 a partir de una introducción y demostración de la conexión de estos con la serie Taylor de orden 2, estos métodos son: el método de Heun, el método de punto medio y El método de Ralston. Se observará a partir de la solución de ecuaciones diferenciales de prueba su respectivo error con respecto a la solución analítica, obteniendo un índice de error dictado por el error cuadrático medio EMC. A través de este documento conoceremos la mejor aproximación numérica a la solución analítica de los diferentes PVI (problemas de valor inicial) planteados, también fijando un patrón de solución para ciertos problemas, es decir, se estipulará el método apropiado para cada tipo de problema. Se observo que método de Ralston presentó mayor exactitud seguido por el método del punto medio y el de Heun, en los demás PVI se observa que el método del punto medio proporciona la mejor solución numérica puesto que tiene un EMC muy bajo y difícil de alcanzar por los demás métodos.

Palabras claves - aproximación, ecuaciones diferenciales, Heun, problemas de valor inicial, punto medio, Ralston, serie, solución analítica, solución numérica.

\section{INTRODUCTION}

$\mathrm{T}$ he first attempts to solve physical problems by differential calculus at the end of the seventeenth century gradually led to the creation of a new branch of mathematics, namely, differential equations. In the mid-eighteenth-century differential equations became an independent branch and its resolution an end in itself. Mathematicians of the time often used physical arguments: if $\mathrm{y}(\mathrm{x})$ denotes the position at time $\mathrm{t}$ of a particle, then $d y / d x$ is its velocity. If $d y / d x=0$, we have that the velocity is zero, that is, the particle does not move and its position, therefore, remains constant. In 1693 Huygens speaks explicitly of differential equations and in the same year, Leibniz says that differential equations are functions of

Basic Faculty, Mathematics department. They all belong to the research group of GIMAE (femesa@utp.edu.co,dmdevian@utp.edu.co, gecove@utp.edu.co). 
elements of the characteristic triangle, as show in figure 1[1].

At the end of the XXVII century and during the next 100 years' great characters such as Johann Bernoulli, Jean Le Rond d'Alembert, Joseph-Louis Lagrange, Joseph Fourier concentrated on the problem of constructing structures that could solve the different types of differential equations.

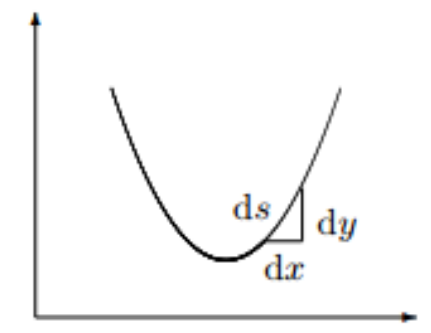

Fig. 1: The characteristic triangle. [1]

At the beginning of the nineteenth century, more precisely in 1820, Cauchy proved the existence of solutions of the differential equation $\mathrm{y}^{\prime}=\mathrm{f}(\mathrm{x}, \mathrm{y})$ under certain conditions. In 1890 Picard established a method of successive approximations that allows to establish with precision the theorem of existence and un iqueness of the differential equations of order $n$. Poincaré's research on the stability and periodicity of solar system solutions led him to the beginning of the theory of nonlinear differential equations. He obtained at the end of the 19th century a series of qualitative results that were improved by Bendixson and by Liapunov [1] [2].

\section{CONTENT}

\section{Ordinary differential equations.}

The solution of ordinary differential equations of the form (1) has a wide margin of study in the field of applied mathematics, the functions ( $\mathrm{f}(\mathrm{x}, \mathrm{y})$ ) represent physical quantities, the derivatives represent their rate of change and the equation defines the relationship between them. Differential equations can then describe physical phenomena and their behavior in certain time intervals, so they play an essential role in various fields such as engineering, economics, physics, chemistry, among others.

$$
\frac{d y}{d x}=f(x, y)
$$

As mentioned above, one of the major concerns in the subject was the creation of procedures that would allow finding the exact solution to the differential equations, however, in some cases this analytical solution could not be found and that is where the implementation is necessary. of the numerical analysis to obtain a solution with a certain degree of accuracy. [3]

\section{Analytical solution}

There are different solution techniques for the EDOs of the structure they have, you can use methods that integrate analytics for problems of separable variables, for example.
Some equations are simpler to solve and require more cumbersome techniques, even so, for non-linear EDOs and for some linear EDOs there are no general methods, that is, they do not have an analytical solution.

\section{Numerical solution of initial value problems (PVI)}

As mentioned above, an analytical solution has been shared, edited, found, simplified, or simplified. The use of numerical methods is necessary.

To find an approximate solution to the ODEs, it is necessary to define some concepts:

The PVI (initial value problem), consists of an ordinary differential equation, as shown in (1):

$$
\frac{d y}{d x}=f(x, y)
$$

Which is subject to an initial condition $y\left(x_{0}\right)=y_{0}$

$$
x_{0} \leq x \leq x_{n}
$$

The numerical solution that will be obtained will not be a continuous approximation to the solution $\mathrm{y}(\mathrm{x})$, but an approximation discretized in several values called mesh points, this solution will have $\mathrm{n}$ points, with abscissas equally spaced by a length of size $\mathrm{h}$ over $\left[x_{0}, x_{n}\right]$. Therefore, the numerical solution will be determined by the advance of points $x_{i}$ y $y_{i}$ :

$$
\begin{gathered}
h=\frac{x_{n}-x_{0}}{n} \\
x_{i}=x_{i-1}+h \\
y_{i}=y_{i-1}+h \cdot \phi\left(x_{i-1}, y_{i-1}, h\right) \\
\text { para todo } i=1,2,3, \ldots, n
\end{gathered}
$$

Where the function $\varphi$ is called the increment function and behaves like the slope of the local linear approximation in the vicinity of the point $\left(x_{(i-1)}, y_{(i-1)}\right)$, this function varies depending on the numerical method used, the form of the calculation of the $y_{i}$ also varies, while the calculation of the $x_{i}$ is equal for all the methods. Therefore the equations seen in (2) generate the set of points $\left\{\left(x_{i}, y_{i}\right)\right\}[4][5]$.

Once the approximate solution is obtained at the points, the approximate solution at other points in the interval can be found through interpolation. [4]

\section{Taylor series to solve EDOs}

The Taylor series (3) is a tool that allows you to obtain local approximations for a function around a point, in terms of the function and its derivatives of higher order. The PVI provides the first derivative of the function, solution of the differential equation and the coordinate of a point that satisfies the solution. In addition, you can calculate the higher-order derivatives of the 
solution field, if they exist.

$$
\begin{gathered}
y(x)=y(a)+y^{\prime}(a)+\frac{y^{\prime \prime}(a)}{2 !}(x-a)^{2}+\cdots \\
+\frac{y^{n}(a)}{n !}(x-a)^{n} \\
y(x)=y\left(x_{0}\right)+y^{\prime}\left(x_{0}\right)\left(x-x_{0}\right)+\frac{y^{\prime \prime}\left(x_{0}\right)}{2 !}\left(x-x_{0}\right)^{2}+\cdots \\
+\frac{y^{n}\left(x_{0}\right)}{n !}\left(x-x_{0}\right)^{n}
\end{gathered}
$$

As previously mentioned in (2), the extrapolation of points $x_{i}$ it obtains:

$$
x_{1}=x_{0}+h
$$

This value is replaced in the Taylor series:

$$
\begin{gathered}
y\left(x_{1}\right)=y\left(x_{0}\right)+y^{\prime}\left(x_{0}\right)\left(x_{0}+h-x_{0}\right) \\
+\frac{y^{\prime \prime}\left(x_{0}\right)}{2 !}\left(x_{0}+h-x_{0}\right)^{2}+\cdots \\
+\frac{y^{n}\left(x_{0}\right)}{n !}\left(x_{0}+h-x_{0}\right)^{n} \\
y\left(x_{1}\right)=y\left(x_{0}\right)+y^{\prime}\left(x_{0}\right) h+\frac{y^{\prime \prime}\left(x_{0}\right)}{2 !} h^{2}+\cdots+\frac{y^{n}\left(x_{0}\right)}{n !} h^{n}
\end{gathered}
$$

From this it follows that $\mathrm{y}\left(x_{i}\right)=y_{i}$, therefore the previous result is denoted as:

$$
y_{1}=y_{0}+y^{\prime}\left(x_{0}\right) h+\frac{y^{\prime \prime}\left(x_{0}\right)}{2 !} h^{2}+\cdots+\frac{y^{n}\left(x_{0}\right)}{n !} h^{n}
$$

Then, with $y_{1}$ it is possible to obtain $y_{2}$, in the following way:

$$
y_{2}=y_{1}+y^{\prime}\left(x_{1}\right) h+\frac{y^{\prime \prime}\left(x_{1}\right)}{2 !} h^{2}+\cdots+\frac{y^{n}\left(x_{1}\right)}{n !} h^{n}
$$

Generalizing, if $\left(x_{i-1}, y_{i-1}\right)$ extrapolates to $\left(x_{i}, y_{i}\right)$, then:

$$
y_{i}=y_{i-1}+y^{\prime}\left(x_{i-1}\right) h+\frac{y^{\prime \prime}\left(x_{i-1}\right)}{2 !} h^{2}+\cdots+\frac{y^{n}\left(x_{i-1}\right)}{n !} h^{n}
$$

It has that as $y^{\prime}(x)=f(x, y)$ of (1) then the derivatives of higher order are given by

$$
\begin{gathered}
y^{\prime \prime}(x)=f^{\prime}(x, y) \\
y^{\prime \prime \prime}(x)=f^{\prime \prime}(x, y) \\
\vdots \\
y^{n}(x)=f^{n-1}(x, y) \\
y_{i}=y_{i-1}+f\left(x_{i-1}, y_{i-1}\right) h+\frac{f^{\prime}\left(x_{i-1}, y_{i-1}\right)}{2 !} h^{2}+\cdots \\
+\frac{f^{n-1}\left(x_{i-1}, y_{i-1}\right)}{n !} h^{n}
\end{gathered}
$$

Subsequently, $\mathrm{h}$ is factored:

$$
\begin{gathered}
y_{i}=y_{i-1}+h\left[f\left(x_{i-1}, y_{i-1}\right)+\frac{f^{\prime}\left(x_{i-1}, y_{i-1}\right)}{2 !} h+\cdots\right. \\
+\frac{f^{n-1}\left(x_{i-1}, y_{i-1}\right)}{n !} h^{n-1}
\end{gathered}
$$

What finally agrees with the set of points generated.

$y_{i}$, with $i=1,2, \ldots, n$, de (2):

$$
y_{i}=y_{i-1}+h \cdot \phi\left(x_{i-1}, y_{i-1}, h\right)
$$

Donde:

$$
\begin{aligned}
\phi\left(x_{i-1}, y_{i-1}, h\right)= & f\left(x_{i}, y_{i}\right)+\frac{f^{\prime\left(x_{i}, y_{i}\right)}}{2 !} h+\cdots \\
& +\frac{f^{n-1}\left(x_{i}, y_{i}\right)}{n !} h^{n-1}
\end{aligned}
$$

\section{Runge-Kutta methods}

The Runge-Kutta $(R K)$ methods achieve the accuracy of the Taylor series procedure without requiring the calculation of higher order derivatives. There are many variants, but all have the generalized form of the equations (2), the most important thing to study of these methods is the increment function that for these methods is written in general form as:

$$
\phi=a_{1} k_{1}+a_{2} k_{2}+\cdots+a_{n} k_{n}
$$

Where the $a$ 's are constant and the $k^{\prime} s$ are:

$$
\begin{gathered}
k_{1}=f\left(x_{i}, y_{i}\right) \\
k_{2}=f\left(x_{i}+p_{1} h, y_{i}+q_{11} k_{1} h\right) \\
k_{3}=f\left(x_{i}+p_{2} h, y_{i}+q_{21} k_{1} h+q_{22} k_{2} h\right) \\
\vdots \\
k_{n}=f\left(x_{i}+p_{n-1} h, y_{i}+q_{n-1,1} k_{1} h+q_{n-1,2} k_{2} h+\cdots\right. \\
\left.+q_{n-1, n-2} k_{n-2} h+q_{n-1, n-1} k_{n-1} h\right)
\end{gathered}
$$

Where $p$ and $q$ are constant. It can be seen that the $\mathrm{k}$ are relational relationships. That is, $k_{1}$ appears in the equation $k_{2}$, which appears in the equation $k_{3}$, and so on. Since each $\mathrm{k}$ is a functional evaluation, this recurrence makes the $R K$ methods for computer calculations efficient. It is possible to have several types of Runge-Kutta methods using different numbers of terms in the increment function specified by $\mathrm{n}$. Here the first-order Runge-Kutta (RK) method with $\mathrm{n}=1$ is, in fact, the Euler method. [3] [5]

\section{Second-order Runge-Kutta methods}

Second-order RK methods use the increment function with two terms $(n=2)$. Those second order methods will be exact if the solution of the differential equation is quadratic. In addition, since the terms with $h_{3}$ and greater are eliminated during the deduction, the local truncation error is $\mathrm{O}\left(h_{3}\right)$ and the global truncation error is $\mathrm{O}\left(h_{2}\right)$. The second-order version of equation 
(2) is:

$$
y_{i+1}=y_{i}+\left(a_{1} k_{1}+a_{2} k_{2}\right) h
$$

Where:

$$
\begin{gathered}
k_{1}=f\left(x_{i}, y_{i}\right) \quad \mathrm{y} \\
k_{2}=f\left(x_{i}+p_{1} h, y_{i}+q_{11} k_{1} h\right)
\end{gathered}
$$

The basic strategy of the Runge-Kutta methods is the use of algebraic manipulations to obtain the values of $a_{1}, a_{2}, p_{1}$ and $q_{11}$, so we must have the Taylor series of order 2 :

$$
y_{i+1}=y_{i}+f\left(x_{i}, y_{i}\right) h+\frac{f^{\prime}\left(x_{i-1}, y_{i-1}\right)}{2 !} h^{2}
$$

y

$$
f^{\prime}\left(x_{i-1}, y_{i-1}\right)=\frac{\partial f(x, y)}{\partial x}+\frac{\partial f(x, y)}{\partial y} \frac{d y}{d x}
$$

Substituting (9) in (8) we have:

$$
\begin{aligned}
& y_{i+1}=y_{i}+f\left(x_{i}, y_{i}\right) h \\
&+\left(\frac{\partial f(x, y)}{\partial x}+\frac{\partial f(x, y)}{\partial y} \frac{d y}{d x}\right) \frac{h^{2}}{2 !}
\end{aligned}
$$

Later it is observed that the Taylor series for a function of two variables, specifically the Taylor series of order 2 for $k_{2}$ in (7) is:

$$
\begin{aligned}
& k_{2}=f\left(x_{i}+p_{1} h, y_{i}+q_{11} k_{1} h\right)= \\
& \quad f\left(x_{i}, y_{i}\right)+p_{1} h \frac{\partial f}{\partial x}+q_{11} k_{1} h \frac{\partial f}{\partial y}
\end{aligned}
$$

Replacing the value of $k_{2}$, obtained in (11), and of $k_{1}$, in (7), within (6) we have:

$$
\begin{aligned}
y_{i+1}=y_{i}+a_{1} f( & \left.x_{i}, y_{i}\right) h+a_{2} f\left(x_{i}, y_{i}\right) h \\
& +\left(a_{2} p_{1} \frac{\partial f(x, y)}{\partial x} h^{2}\right. \\
& \left.+a_{2} p_{1} \frac{\partial f(x, y)}{\partial y} h^{2}\right)
\end{aligned}
$$

Finally, by means of a comparison between (10) and (12) the following relations can be obtained for the constants $a_{1}, a_{2}, p_{1}$ and $q_{11}$ :

$$
\begin{gathered}
a_{1}+a_{2}=1 \\
a_{2} p_{1}=\frac{1}{2} \\
a_{2} q_{11}=\frac{1}{2}
\end{gathered}
$$

The three previous equations contain the four unknown constants. Since there is one more mystery than the number of equations, there is no single set of constants that satisfies the equations. However, considering a value for one of the constants, it is possible to determine the value of the other three. Consequently, there is a family of second order methods and not a single version. [2] [5] For practical purposes in this paper, only three methods related to the value of the constant a_2 will be exposed: Heun's method, the midpoint method and Ralston's method

\section{Heun method}

In this method we have a fixed value of $a_{2}=1 / 2$, so the other constants of (13) are: $a_{1}=1 / 2, p_{1}=1, q_{11}=1$ hence, equation (6) for Heun's method is :

$$
y_{i+1}=y_{i}+\left(\frac{1}{2} k_{1}+\frac{1}{2} k_{2}\right) h
$$

Where:

$$
\begin{gathered}
k_{1}=f\left(x_{i}, y_{i}\right) \\
\text { y } k_{2}=f\left(x_{i}+h, y_{i}+k_{1} h\right)
\end{gathered}
$$

\section{Midpoint method}

In this method we have a fixed value of $a_{2}=1$, so the other constants of (13) are: $a_{1}=0$

$$
\begin{aligned}
& p_{1}=1 / 2 \\
& q_{11}=1 / 2
\end{aligned}
$$

Hence, equation (6) for the midpoint method is :

$$
y_{i+1}=y_{i}+\frac{1}{2} k_{2} h
$$

Where:

$$
\begin{gathered}
k_{1}=f\left(x_{i}, y_{i}\right) \\
\text { y } k_{2}=f\left(x_{i}+\frac{1}{2} h, y_{i}+\frac{1}{2} k_{1} h\right)
\end{gathered}
$$

\section{Ralston method}

In this method we have a fixed value of $a_{2}=2 / 3$, so the other constants of (13) are: $a_{1}=1 / 3$

$p_{1}=3 / 4$

$q_{11}=3 / 4$

Hence, the midpoint method is presented in (6):

$$
y_{i+1}=y_{i}+\left(\frac{1}{3} k_{1}+\frac{2}{3} k_{2}\right) h
$$

Where:

$$
\begin{gathered}
k_{1}=f\left(x_{i}, y_{i}\right) \\
\text { y } k_{2}=f\left(x_{i}+\frac{3}{4} h, y_{i}+\frac{3}{4} k_{1} h\right)
\end{gathered}
$$




\section{Test problems}

To guarantee the realization of an effective comparison between the Runge Kutta methods of order 2, these will be implemented to solve different differential equations, to observe the accuracy of each one in several scenarios. Next, the initial value problems (PVI) with their corresponding analytical response are presented.

\section{PVI 1}

$$
\frac{d y}{d x}=-2 x^{3}+12 x^{2}-20 x+8.5[3]
$$

With initial condition $y(0)=1$, analytical solution:

$$
y(x)=-\frac{1}{2} x^{4}+4 x^{3}-10 x^{2}+8.5 x+1
$$

PVI 2

$$
\frac{d y}{d x}=\frac{y}{1+x^{2}}[5]
$$

With initial condition $\mathrm{y}(0)=1$, analytical solution:

$$
y(x)=e^{\arctan (x)}
$$

PVI 3

$$
\frac{d y}{d x}=y \operatorname{sen}^{3}(x)[4]
$$

With initial condition $y(0)=1$, analytical solution:

$$
y(x)=e^{\frac{\cos ^{3}(x)}{3}-\cos (x)+2 / 3}
$$

\section{Calculation of the error}

The truncation error of the series is used in the numerical methods for solving initial value problems. Of Taylor to measure the approximation to the exact response of the differential equation, however, the methods discussed in this paper are the Runge-Kutta methods of order 2, which include some artifacts that distance them from the Taylor series of order 2 , which is why it is decided to implement the mean square error (EMC) for each point of the grid of the numerical solution of each method, that is:

$$
E C M=\frac{1}{n} \sum_{i=1}^{n}\left[y_{i}-y_{i}^{*}\right]^{2},
$$

Where $y_{i}^{*}$ is the value of the ordinate obtained from evaluating $x_{i}$ in the exact (analytical) solution of the differential equation, $y_{i}$ corresponds to the value of the ordinate of the numerical solution of each method obtained according to:

$$
y_{i}=y_{0}+h \cdot \phi
$$

$\phi$ is the increment function, which varies according to the method implemented [8]

\section{RESULTS}

Below are the results of solving the three initial value problems presented above, each problem was solved in the interval $0 \leq \mathrm{x} \leq 4$, so the points $x_{i}$ are defined in the same way for each of the solutions

\begin{tabular}{|l|l|l|l|l|l|l|l|l|}
\hline$x_{i}$ & 0.0 & 0.5 & 1.0 & 1.5 & 5.0 & 2.5 & 3.0 & 3.5 \\
\hline
\end{tabular}

Based on these points, the numerical solutions will be presented in a graphical way, to observe the differences in the methods

\section{PVI 1}

$$
\frac{d y}{d x}=-2 x^{3}+12 x^{2}-20 x+8.5
$$

With initial condition $y(0)=1$, analytical solution:

$$
y(x)=-\frac{1}{2} x^{4}+4 x^{3}-10 x^{2}+8.5 x+1
$$

The comparisons of the numerical solutions used with the methods used against the exact analytical solution to PVI 1 are shown in Table 1.

TABLE 1

\begin{tabular}{llll}
\begin{tabular}{l} 
COMPARATIVE NUMERICAL SOLUTION TO PVI \\
\hline \hline $\begin{array}{l}\text { Middle } \\
\text { point }\end{array}$
\end{tabular} & Heun & Ralston & $\begin{array}{l}\text { Exact } \\
\text { Solution }\end{array}$ \\
\hline 1.0000 & 1.0000 & 1.0000 & 1.0000 \\
3.1093 & 3.4375 & 3.2773 & 3.2187 \\
2.8125 & 3.3750 & 3.1016 & 3.0000 \\
1.9844 & 2.6875 & 2.3477 & 2.2187 \\
1.7500 & 2.5000 & 2.1406 & 2.0000 \\
2.4844 & 3.1875 & 2.8555 & 2.7187 \\
3.8125 & 4.3750 & 4.1172 & 4.0000 \\
4.6093 & 4.9375 & 4.8008 & 4.7187 \\
3.0000 & 3.0000 & 3.0313 & 3.0000 \\
\hline \hline
\end{tabular}

The comparisons of the graphical solutions obtained with the exposed methods against the exact analytical solution to PVI 1 are observed in Figure 2. 


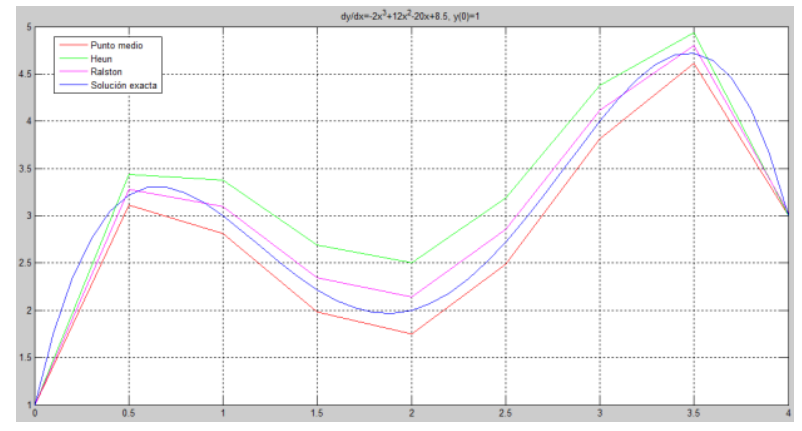

Fig. 2. Comparative graphical solution of PVI 1

PVI 2

$$
\frac{d y}{d x}=\frac{y}{1+x^{2}}
$$

With initial condition $y(0)=1$, analytical solution:

$$
y(x)=e^{\arctan (x)}
$$

Table 2 shows the comparisons of the numerical solutions obtained with the methods presented against the exact analytical solution to PVI 2.

TABLE 2

\begin{tabular}{llll}
\multicolumn{4}{l}{ COMPARATIVE NUMERICAL SOLUTION TO PVI2 } \\
\hline \hline $\begin{array}{l}\text { Middle } \\
\text { point }\end{array}$ & Heun & Ralston & $\begin{array}{l}\text { Exact } \\
\text { Solution }\end{array}$ \\
\hline 1.0000 & 1.0000 & 1.0000 & 1.0000 \\
1.5882 & 1.5500 & 1.5685 & 1.5898 \\
2.1981 & 2.1312 & 2.1626 & 2.1932 \\
2.6806 & 2.6025 & 2.6389 & 2.6719 \\
3.0359 & 2.9529 & 2.9915 & 3.0257 \\
3.2988 & 3.2125 & 3.2527 & 3.2880 \\
3.4981 & 3.4092 & 3.4505 & 3.4870 \\
3.6531 & 3.5619 & 3.6043 & 3.6418 \\
3.7767 & 3.6836 & 3.7268 & 3.7653 \\
& & & \\
\hline \hline
\end{tabular}

The comparisons of the graphical solutions obtained with the exposed methods versus the exact analytical solution to PVI 2 are observed in figure 3 .

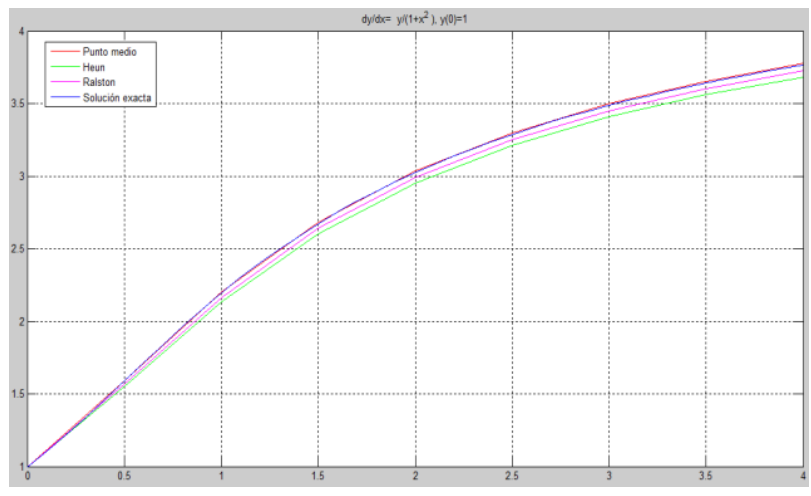

Fig. 3. Comparative graphical solution of PVI 2
A. PVI 3

$$
\frac{d y}{d x}=\operatorname{ysen}^{3}(x)
$$

With initial condition $y(0)=1$, analytical solution:

$$
y(x)=e^{\frac{\cos ^{3}(x)}{3}-\cos (x)+2 / 3}
$$

The comparisons of the numerical solutions obtained with the exposed methods versus the exact analytical solution to PVI 3 are shown in table 3 .

TABLE 3

\begin{tabular}{cccr}
$\begin{array}{c}\text { MoMPARATIVE NUMERICAL SOLUTION TO PVI 3 } \\
\text { point }\end{array}$ & Heun & Ralston & $\begin{array}{r}\text { Exact } \\
\text { Solution }\end{array}$ \\
\hline \hline 1.0000 & 1.0000 & 1.0000 & 1.0000 \\
1.0075 & 1.0275 & 1.0164 & 1.0144 \\
1.1715 & 1.2173 & 1.1946 & 1.1959 \\
1.7466 & 1.7907 & 1.1946 & 1.8149 \\
2.7852 & 2.7386 & 2.7705 & 2.8828 \\
3.5644 & 3.4553 & 3.5129 & 3.6561 \\
3.6688 & 3.6431 & 3.5129 & 3.7932 \\
3.6665 & 3.6063 & 3.6481 & 3.7787 \\
3.3279 & 3.1851 & 3.2630 & 3.4117 \\
\hline \hline
\end{tabular}

Figure 4 shows the comparisons of the graphical solutions obtained with the exposed methods versus the exact analytical solution at PVI 3.

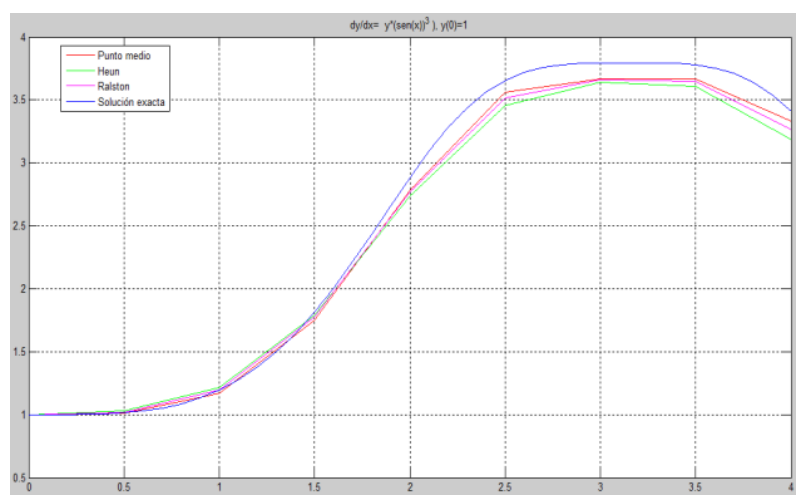

Fig. 4. Comparative graphical solution of the PVI 3

\section{Mean Square Error.}

Table 4 shows the root mean square error calculations.

TABLE 4

RESULTS OF THE MEAN SQUARE ERROR OF THE METHODS IN EACH PVI

\begin{tabular}{cccc}
\hline \hline & & & \\
& PVI 1 & PVI 2 & PVI 3 \\
\hline Middle point & 0.0296 & $7.8 \mathrm{E}-05$ & 0.0065 \\
Heun & 0.1185 & 0.0045 & 0.0184 \\
Ralston & 0.0100 & 0.0010 & 0.0102 \\
& & & \\
\hline \hline
\end{tabular}




\section{CONCLUSIONS}

The development of different numerical methods for the solution of differential equations facilitates the study and application of them. In the comparison made it can be seen that depending on the problem to solve some methods are a little better, for example, in the solution of PVI 1, which is a differential equation of a polynomial of degree 4, the Ralston method presented greater accuracy followed by the midpoint method and the Heun method, in the other PVI it is observed that the midpoint method yields the best numerical solution since it has a very low EMC and difficult to reach by the other methods, it is possible to conclude that the veracity of the method is because intrinsically this takes more mesh points for the solution as its name says; will take in addition to the normal mesh points, the intermediate points between these. The realization of the presented methods, shows the simplicity in the implementation, relationship between these and the error in the solution with respect to the exact answers, the obtaining of these numerical solutions expose the simplicity of the Runge-Kutta methods and the saving of computational effort compared to the Taylor seers of higher order. This document and practical elaborations serve as a pillar for future comparisons in more advanced methods, such as the 3rd order and higher order Runge-Kutta methods, which give closer approximations and are widely used in different types of software.

\section{REFERENCES}

[1] M. Kline and M. Martínez, "El pensamiento matemático de la Antigüedad a nuestros días", Alianza Editorial, Madrid, España, 1992.

[2] Turnbull.mcs.st-and.ac.uk, MacTutor History of Mathematics. [online] Available at: http://turnbull.mcs.st-and.ac.uk/history/, 2018.

[3] S. C. Chapra and R.P Canale, "Métodos numéricos para ingenieros”, McGraw-Hill, México, 2015.

[4] A. Doucet, N. Gordon, "An introduction to sequential monte carlo methods, Chapter in Sequential Monte Carlo Methods in Practice", Springer, pp. 3-14, 2001. doi: 10.1007/978-1-4757-3437-9 1

[5] A. Quarteroni, R. Sacco and F. Saleri, "Numerical mathematics", Springer Science \& Business Media, 2010.

[6] J. M. Ledanois, "Métodos numéricos aplicados en ingeniería", McGraw-Hill, Venezuela, 2000.

[7] J. H. Mathews and K.D. Fink, "Métodos numéricos con Matlab", Pearson, Madrid, España, 2000.

[8] F. Mesa, P. P. Cárdenas, C. A. Rodríguez, "Comparison of the Conjugate Gradient Methods of Liu-Storey and Dai-Yuan", Contemporary Engineering Sciences, vol. 10, no. 35, pp. 17191726, 2017. doi: 10.12988/ces.2017.711189

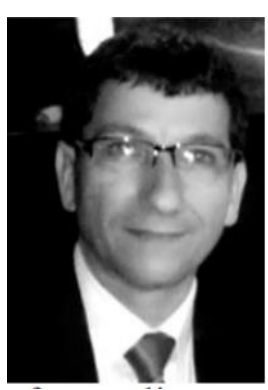

Fernando Mesa, university professor of the Mathematics Department of the Technological University of Pereira, Colombia and director of the applied mathematics and education research group. Master of Science (Msc) in physical instrumentation (2007). Member of the plasma laboratory of the National University of Colombia, located in Manizales, Colombia. Member of the group of non-linear differential equations "GEDNOL" at the Technological University of Pereira, Colombia. Director of the research group in Applied Mathematics and Education "GIMAE" at the Technological University of Pereira, Colombia. https://orcid.org/0000-0002-3418-5555

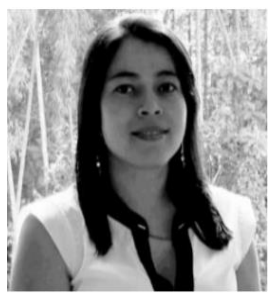

Diana Marcela Devia Narváez. Associated teacher of mathematics and physics at Universidad Tecnologica de Pereira, Colombia. $\mathrm{PhD}$ in engineering (2012). Master of Science (Msc) in the faculty of Physics - Cience (2010). Member of plasma laboratory from Universidad Nacional de Colombia located in Manizales, Colombia. Member of nonlinear differential equations group "GEDNOL" at Universidad Tecnológica de Pereira, Colombia. Area of expertise: material processing through assisted plasma techniques, structural characterization mechanical of materials, simulation and modeling of material's physical properties. https://orcid.org/0000-0002-0447-4663

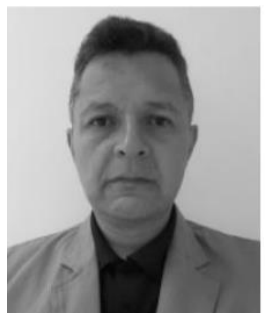

German Correa Vélez, university lecturer of the department of Mathematics at the Universidad Tecnológica de Pereira, Colombia. Master of Science (Msc) in mathematics (2008). Member of nonlinear differential equations group "GEDNOL" at Universidad Tecnologica de Pereira, Colombia. Member of the research group in Applied Mathematics and Education "GIMAE" at the Universidad Tecnológica de Pereira. https://orcid.org/00000002-5244-3095 